\title{
PEDAGOGICAL REGRESSION THROUGH SERVICE-LEARNING DEVELOPS THE HOLISTIC MEDICAL GRADUATE BY REDEFINING RECIPROCITY
}

\author{
R. Botha* \\ Community Based Education and Rural Health \\ e-mail: BothaRW@ufs.ac.za / http://orcid.org/0000-0002-0231-8085 \\ J. Bezuidenhout ${ }^{*}$ \\ Health Professions Education \\ e-mail: BezuidJ@ufs.ac.za / https://orcid.org/0000-0002-4612-5648 \\ *University of the Free State \\ Bloemfontein, South Africa
}

\section{ABSTRACT}

Pedagogical regression through Service-learning uses dialogue and deliberation as active learning tools. Reciprocity is a consequence rooted in this engagement with diverse communities. The aim of the study was to analyse how reciprocity manifests during service-learning. Data collected from students, Grade 12 learners, radiography facilitators, and conference delegates were analysed. Students indicated that service-learning enhanced their learning through selfdiscovery and group interactions, but nothing academic was learned from the learners. They experienced personal growth and increased levels of social responsiveness. Grade 12 learners reported no educational exchange with the students. Radiography facilitators agreed that servicelearning cultivates reciprocity through application of knowledge and elevates personal growth and social responsiveness in students. Conference delegates said that service-learning enhances the curriculum and cultivates social responsiveness in students. Reciprocity in service-learning is polygonal and needs to be redefined in terms of its equal mutualistic nature, of all communities benefitting from a broadly defined exchange.

Keywords: service-learning, reciprocity, student development, hidden community, social responsiveness

\section{INTRODUCTION}

Before hieroglyphics, before papyrus, before pedagogy, before the Bachelor's and before the Internet, experience and word of mouth were the tools of information dissemination and formal education. The establishment of tertiary education caused education to become exclusive, which is in direct contrast to the origin of education. Pedagogical regression can be described as a means of regressing teaching and learning to the oral tradition of storytelling and to 
survivalist self-taught. Service-learning takes teaching and learning back to its back to its origins, where pedagogical regression is directly proportional to societal progression. In South Africa, societal progression through the dissemination of health information, service provision and access to resources, poses great challenges.

In response to these challenges, service-learning is directed at specific community needs and implies applied learning integrated into an academic programme. Service-learning could be credit-bearing and should be assessed (HEQC 2004, 26). A more comprehensive definition of service-learning is

"a course-based, credit-bearing educational experience in which students (a) participate in an organized service activity that meets identified community needs and (b) reflect on the service activity in such a way as to gain further understanding of course content, a broader appreciation of the discipline, and an enhanced sense of civic responsibility" (Bringle and Hatcher 1995, 112).

The development of the holistic medical graduate is achievable through providing experiences that will enable observation, assimilation and application, as outlined by Kolb's experiential learning cycle (Kolb 1984, 30). In a service-learning context, the cycle describes how students migrate from direct experience (in a community-service context), to action (in the clinicalservice context), where experience and action are linked by reflection and abstract formulation. The service-learning experience develops the holistic graduate through its philosophy of equal partnerships, personal growth, social responsiveness and the reciprocal "interplay between teaching and learning" (Donahue, Bowyer and Rosenberg 2003, 17) within a multicultural society. Service-learning relies on the inclusive relationship between communities and tertiary institutions; knowledge generation and social dissemination has a reciprocal effect on academe (HEQC CHE 2006).

Service-learning affiliates itself with a myriad of learning theories, among others, cognitivism, behaviourism and constructivism. Cognitivism focusses on the conceptualisation of students' processes associated with learning: the way data is received, organised, deposited, and retrieved, including using language, reasoning and solving problems (Ertmer and Newby $2013,51)$. Vygotsky $(1978,32)$ believes that social learning leads to cognitive learning, which is made possible through reciprocal interactions with community members. Behaviourism refers to learning due to changes in observation when students display the justified situational response after their exposure to a specific environmental stimulus. Behaviourism describes the application of knowledge in a new context, and symbolises a relationship between prior learning and new learning. Constructivism in service-learning activities is demonstrated by enabling students to complete the puzzle of knowledge to a systematic unit. Unlike cognitivism and 
behaviourism, constructivism infers that knowledge is mind-dependent, and can be "mapped onto a learner" (Ertmer and Newby 2013, 55) through scaffolding of learning activities. Constructivists believe that our knowledge of the world is founded on our interpretations of our experiences. Service-learning interaction with communities, planning, preparation, execution and reflection enable students to improve their understanding, and to construct meaning, and meaning ultimately changes behaviour.

\section{LITERATURE REVIEW}

Hurd (2006, Online) reflects that service-learning promote student participation and involvement in their own learning and therefor captures models of active learning. Active learning instructional approaches associated with service-learning include participatory lectures, group discussions, student panels and debates. Service-learning activities and resources relies on students' individual experiences, creativity and knowledge, and community interaction, to expand and vary the intellectual resources accessible to students. Servicelearning also reveals assumptions, values, beliefs, and feelings that shapes (positively or negatively) how students react to new learning. The structured reflection used in servicelearning allows students to link their service experiences to exit-level outcomes, learning outcomes, graduate attributes, and course objectives. Through service-learning students develop a deeper understanding of module content by addressing complex problems in their authentic contexts. Service-learning promotes practical strategies for the transfer of knowledge and problem-solving skills to new situations. In this instance, the author refer to the application of knowledge: the activities associated with service-learning implementation should be structured, so that community engagement enhances academic learning, without replacing academic learning. Additionally, reciprocity among providers and recipients of services is evident when "power is seen as something to be shared" Merz and Furman (1997, 13).

Buy-in, equal participation, joint decision-making, and ownership by external stakeholders, including communities, is at the core of all community-based educational experiences. Communities are equal partners in identifying service needs and development challenges. Merz and Furman $(1997,13)$ mention that, when institutions of higher learning interact with a community, the relationship can be characterised by both gesellschaft and gemeinschaft. Gesellschaft (which is intentional) is a German word that refers to people coming together to achieve specific goals, e.g., a student tutors a struggling third grader, while gemeinschaft (involuntary) refers to people coming together due to commonality, e.g., traditional relationships based on relative location, familial bonds, or friendship. Unfortunately, most partnerships can be viewed as being gesellschaftlich in nature, the notion of the university 
bringing expertise and services to clients, as a consequence "power is not equally shared" (Merz and Furman 1997, 13-14).

Literature discussed reciprocity as a key component of service-learning. When all parties are equally participating, and functioning as both teacher and learner reciprocity manifest. This form of relationship is essential to minimise possible exploitation of both the community and the student (Donahue et al. 2003, 17). Exploitation is minimised by equal power sharing and deliberate efforts by all to increase power for all parties involved. Reciprocity is characterised by the constant interplay between giving and receiving, and teaching and learning. During their students' community placements, Donahue et al. $(2003,18)$ captured the experience and meaning of "learning with" and "learning from". The researchers analysed written and verbal reflections of preservice teachers regarding their service experience. The finding of the study was that the participants were able to move beyond their own distinctiveness towards affinities, due to them sharing valuable information. This two-way academic pathway is also illustrated by preservice teachers improving their understanding of learning institutions and adolescents and how adolescents view school - high school learners were exposed to the complexity of lesson planning. Regression of teaching and learning to the ancient art of verbal communication facilitated reciprocal sharing of knowledge. Pedagogical regression through service-learning not only relates to a knowledge exchange, but can be defined more broadly.

Stanton $(1990,67)$ defines reciprocal learning as a communal and educational exchange between students and the communities that they interact with. If one examines the exchange mentioned here, Sigmon $(1996,43)$ adds that, each participant is server and served, caregiver and recipient of care, contributor and contributed to. Sigmon $(1996,43)$ continues that learning and teaching is undertaken and experienced by all in the service-learning relationship. Servicelearning as a form of experiential education differs as its, "intention to benefit equally the provider and the recipient of the service as well as to ensure equal focus on both the service being provided and the learning that is occurring" (Furco 1996, 5). According to Furco, servicelearning must have an academic context and be designed so that the service enhances the learning and the learning enhances the service. Continuing his analysis of service-learning Stanton $(1990,67)$ argues that this reciprocal approach to teaching and learning influences the purpose, format and manner of the student-community social and educational exchange.

A common thread throughout the paragraphs above is that reciprocity between the community and the students involved in service-learning ensues when there is an equal partnership and an exchange, including an academic exchange. However, Bringle and Hatcher $(2005,27)$ is of the opinion that service-learning does not necessarily yield learning associated with and academic exchange. In this regard, Bringle and Hatcher $(2005,27)$ suggest that 
reciprocity in service-learning refers to more than an educational exchange, but to holistic student development. Service-learning should provide opportunity for knowledge acquisition and personal growth, which is the result of students' service experiences throughout the different stages of execution. This is achieved by consulted, explicit, content-driven and outcomes-based commitments.

Another shared view in the above sections is that the community is regarded as a separate entity rather than part of an intricate network of interdependent communities. Teaching and learning practices, such as service-learning, should cultivate individuals who have a knowingness, an inquisitiveness and a socially emancipated spirit. This critical consciousness refers to individuals' understanding of their world and how individual, social and political circumstances contribute to their understanding of this reality (Garner 2014, 1272). Where interaction with a multidimensional multi-layered network of communities provides this realisation. Cultivating individuals who demonstrate empathy and a sense of belonging and whose learning is not confined to the covers of a textbook, is achievable through pedagogical regression.

Here, the development of the holistic medical graduate is related to personal growth, which refers to self-improvement and self-actualisation. Service-learning improves students' self-confidence, self-esteem and self-understanding, by enabling them to acquire a sense of identity, belonging and autonomy due to being open to new encounters and new roles (Duckenfield and Swanson 1992, 5). Personal growth through service-learning includes acquiring the social skills (social growth) that are necessary to form relationships with different members of society. Examples of these skills at work when engaged with diverse and multicultural communities are communication skills, leadership skills, cooperation and collaboration, a sense of belonging and caring, acceptance and awareness of others, and peer assisiation.

Service-learning heightens students' awareness of their social roles, and by integrating new generations of intellectuals it promotes the enterprise for developing citizenship (Bawa 2003, 52). Citizenship not only entails social responsiveness, but also elements related to personal growth. Service-learning develops the holistic graduate by developing social responsiveness in students. Social responsiveness includes students being aware of the needs of communities, wanting to contribute to society, democratic participation, entrepreneurship and enrichment, and a belief in their individual ability to make a difference.

Celio, Durlak, and Dymnicki $(2011,170)$ analysed 62 studies on impact of servicelearning on students. The findings of these studies are summarised as: civic engagement, which included outcomes concerned with, or directly affecting communities, and improved of 
students' social skills. The studies additionally revealed development of social skills such as leadership, cultural competence, and social problem-solving in which significant growth was evident. The findings indicate that service-learning programmes can benefit students at different levels of education in a variety of ways including positive attitudes and behaviours towards social engagement, and heightened social skills.

In a related study, medical and dental students interacted with Mexican migrants provided feedback on their experiences using questionnaires and journals (Martinez-Mier et al. 2011, 2). Cultural competence skills enable healthcare professionals to effectively and respectfully communicate and treat diverse patient population. This included being able to communicate with an awareness of barriers to health facilities and services. Culturally competent healthcare professionals are able to understand and manage sociocultural factors that influence health beliefs and behaviours appropriately. Martinez-Mier et al. $(2011,10)$ declare that servicelearning connects school-based learning, personal growth and civic responsibility. In servicelearning both the service provided and the learning that takes place are equally important and such programmes should endeavour to balance the two components (Furco 1996, 3).

As pedagogy has progressed over the years to include e-learning, online learning and $\mathrm{m}$ learning, it has become essential to rehumanise education through pedagogical regression. Service-learning offers multiple and various opportunities for holistic student development.

\section{METHODS}

Approval to conduct the study was provided by the Ethics Committee of the Faculty of Health Sciences at the University of the Free State (ECUFS No. 117/2012). The Free State Department of Education, and the schools and tertiary institutions that participated in this study additionally provided approval to conduct the research project.

The community involved in this study were selected purposefully from five schools, using ethnicity and geographical location as criteria. The Grade 12 learners were chosen as the community because of the overlap that exists between the Grade 12 natural and life science curricula with curricular aspects of the academic discipline of radiography. Participating thirdyear radiography students were randomly divided into five groups, and each group allocated a community. Each group of students visited their community (Grade 12 learners) three times in a year. During the first site visit the outcomes were discussed with the Grade 12 learners, as well as logistical matters, such as time frames and roles and responsibilities. During the second visit, students had to achieve outcomes related to medical imaging and associated services in the region, and breast health and mammography. The needs of the Free State Department of Health, the service provider, were addressed by providing information on the topics mentioned. 
The outcomes of the third visit were related to mother and foetal health and obstetric ultrasound, as well as bone health and bone densitometry.

In this study, an adaptation of the structured reflection of Zlotkowski et. al. (HEQC $2006,74)$ was used to gain insight into the academic and social learning of students. The reflective rubrics completed by students after Visits 2 and 3 consisted of two sections: Academic Learning and Enhancement Domain, and Personal Growth and Social Responsiveness Domain. The questions posed in this rubric were also used during the reflection discussions with each group after the visits.

Radiography facilitators from other institutions in South Africa that are engaged in service-learning as described by Bringle and Hatcher $(1995,112)$ completed a questionnaire and were interviewed individually. Topics of questions included graduate attribute skills, including benefits to society, student personal growth and reciprocity. Delegates attending the $42^{\text {nd }}$ annual International Society for Exploring Teaching and Learning (ISETL) conference provided quantitative information related to questions similar to those used during the interviews with South African facilitators. Grade 12 learners were also asked whether they benefitted from the interaction; learners were asked to motivate their answers and provide feedback on how to improve future interaction.

During the discussion sessions the different participating groups (radiography students $(n=130)$, radiography facilitators $(n=5)$, ISETL delegates $(n=5)$ and Grade 12 learners $(n=683))$ were informed of the purpose and objectives of the study. An information sheet was distributed amongst participants and those individuals interested in participating were asked to complete the informed consent form prior to data collection.

\section{RESULTS AND DISCUSSION}

Of the 136 student rubrics distributed, 130 were completed and returned, giving a response rate of 96 per cent $(n=130)$. The return rate for the ISETL conference delegates and the facilitators from three South African institutions who participated in the interviews was 100 per cent in both instances $(n=5) ; 683$ Grade 12 learners completed the questionnaire.

\section{Academic reciprocity}

The redefinition of reciprocity is warranted, because most students commented that they had learned Nothing academic from the Grade 12 learners. Bear in mind that there were science learners among the Grade 12 group, whose natural science curriculum includes two learning units covered by the radiography students in their presentations. The reader needs to be cognisant that the knowledge of the two groups (students and Grade12 learners) cannot be 
compared, as the former group is positioned at the tertiary level, and the second at the secondary level.

Similar answers regarding academic reciprocity were given during the interviews by the student groups. Comments included, "Not really anything", and "We did not learn anything". Other statements were, "Didn't learn anything. The Grade 12s were eager and it motivated us and Nothing, we taught them". No evidence of academic reciprocity between the community and the students was found in students' feedback. Considering the audience and the fact that radiography is a specialised field of study, this was, to some extent, to be expected.

During Visit 2, many students indicated that they learned academic work from their fellow students. Through collaboration with more knowledgeable peers, students were able to improve their own understanding; statement from one of the students: "By hearing them [fellow students] speak about it reinforce the work in your mind". Feedback from students points to the idea of a hidden community within service-learning that allowed for an academic exchange. Reciprocity in service-learning is described as a mutualistic relationship between students and the external community; from the findings it is clear academic reciprocity occurred between student and student. Students participating in service-learning as a group formed a community that enhanced their learning through an academic exchange. According to Vygotsky $(1978,32)$ students' learning and application is influenced positively when they do it under the guidance of or in collaboration with peers. Through group work the classroom becomes a learning community in which students actively takes responsibility for their own learning and contribute to the learning of their peers. The service-learning process within this hidden community "puts theory into context, mixes rigor with relevance, and builds concrete skills" (Richardson 2006, $38)$.

Students had to indicate How the experience enhanced their knowledge of specific outcomes, theory or concepts. The large categories for this theme were, Simplification towards improved understanding, Clarified outcomes and Additional info. Here Simplification speaks to packaging the information to make it palatable for the Grade 12's, which consequently led to students' improved understanding of the material. This consequence presented itself due to the approach of taking teaching and learning back to the community. Similar results were found during the student interviews. With reference to the feedback on revision, students elaborated, "Reinforcement of what we've learned in class"; in reference to collaborative learning one student mentioned, "When I interacted, and I was corrected in something and it improved my understanding". In this instance, research and students' interaction with the hidden community facilitated a student-student exchange. The purpose, planning and rollout of service-learning was structured in a way as to integrate community service and engagement to enhance academic 
learning (HEQC 2004).

Students also mentioned that their knowledge had been challenged, because they had to simplify information. "We had to simplify for matriculants to their level so that they can understand it; we couldn't give in on our terms; we understood it clearly by explaining it to them it also improved our understanding; I forgot certain things that I was reminded of'. Here, service-learning research and preparation facilitated academic learning, and not the interaction with the external community. The fact that students commented that, "We taught them", is a clear indication that the interaction with the Grade 12's was one-sided and not equal.

Academic reciprocity is not always achievable during service-learning in resource-based disciplines, such as radiography, but it was important to find out from other institutions what their experiences were. In answering the question whether service-learning allows students to achieve specific outcomes, the facilitators of all three institutions agreed, "Yes".

The facilitator at Institution 1 (in reference to the management module) added, "I structured it [the service-learning rollout] in such a way; it is like a project also incorporating management skills. They needed to plan and organise. They needed to have a leader and also have some kind of control measures." The facilitator's response refers more to the servicelearning process and student collaboration, rather than reciprocal interaction with the external community.

The facilitators of Institution 2 agreed with the radiography students' feedback: "It is like revision. It makes the picture so much clearer". The facilitators' statement does not indicate any interplay between teaching and learning when students interacted with the external community. In contrast to the other institutions, but similar to Bellner and Pomery's $(2005,91)$ explanation of student retention, the facilitator also said, "You know, also it change their attitudes towards school work. That same attitude changes, also boils over to colleagues. It is a positive sort of horizontal line." The facilitator feedback alludes to a student-student exchange within the hidden community. Additional comments from the facilitator were, "The second years were better with mammography patient care. Being able to give the patients better information when asked questions." Student interaction research and preparation facilitated academic learning, and not the interaction with the external community.

The facilitator of Institution 3 stated, "Yes", reciprocity was achieved at Institution 3 through application of knowledge. This response indicates that the reciprocity achieved was not due to the interplay between students and the external community.

Four of conference delegates were of the opinion that "service-learning allows students to achieve specific outcomes"; one indicated that it is probably true. In relation to the statement, Reciprocity (enhancement of the curriculum) is achievable when doing service-learning, four 
said that this statement is true and one said it is probably true. Feedback from conference delegates correlates with feedback given by South African service-learning facilitators, namely, that the service-learning process, collaboration and exchange within the hidden community, and not the interaction with the external community, that facilitates academic enhancement.

Of the Grade 12 learners, 96 per cent indicated that they benefitted from the servicelearning interaction. When asked why they held this opinion, learners replied that the sessions presented by the students had been "relevant; good, informative and educational; Good explanation of concepts; valuable information; Insightful", and "I gained comprehensive knowledge". The Grade 12 learners indicated that they had had an educational experience, but not an educational exchange with the radiography students, as stated by Stanton $(1990,67)$. The learners' declarations, like those of the students, indicate a one-sided relationship, with no equality: learners were served, contributed to and taught (Sigmon 1996, 43).

\section{Personal growth and social responsiveness reciprocity}

Students indicated that they had been nervous and a bit anxious, but that the overall experience was good; for most, the second visit was a more positive experience which can be attributed to reflection and functioning within the hidden community. Few students experienced difficulty working with the external community. This could either be because students are more socially responsive, and/or because the community was open and receptive to student efforts. It also illustrates that the students were able to move beyond their own distinctiveness towards affinities through the sharing of valuable knowledge. Students indicated that the intervention was executed well and that there are areas that need improvement. Students expressed that the Grade 12 learners' feedback, of "More confidence, practice" and technical feedback related to "slides and presentations" added to the success of the second visit. Immersion in the community affected students' personal growth and their social responsiveness.

Students were asked, What assumptions did you bring to the situation? They also had to indicate, Which of the above proved to be true, and which did not? Most of the assumptions are associated with the success of the presentation, group dynamics and interaction with the external community. There were singular instances where the assumptions proved to be true, such as "Group not prepared", and "Good teamwork" - the assumptions that proved to be true were related to interpersonal group issues. The assumptions that did not prove to be true, were mainly "Bad teamwork" and "Grade 12 learners did not comprehend". This exercise enabled students to build a clearer picture of the hidden community and society and to gear their responses to similar future settings accordingly. This phenomena is alluded to by MartinezMier et al. $(2011,7)$, who state that students agreed or strongly agreed that service-learning 
assisted them to understand different cultures better. When students were asked, How can we improve, the feedback referred to an improvement of social responsiveness as a result of their community exposure and interactions. Some students responded by suggesting "More visits", others said "Longer visits", still others referred to engaging the "Wider community" and "More topics".

Though the "Yes" feedback indicates that the facilitator from Institution 1 believed that service-learning cultivates social responsiveness in students, the facilitator's explanation does not provide enough information about her reasons for believing this - it reflects the facilitator's opinion, and the outcome has not been measured: "because the idea is to install in them that once they are qualified they are working out there and that they should be responsive to the needs of community they work with".

The facilitators from Institution 2 believed that service-learning helps to cultivate social responsiveness in students. They commented, "Yes definite! It made them aware of the need there is for education. So the students feel that they have done something, that they have accomplished something and did something for the community". Students were able to identify (external) community needs and were able to gear their response accordingly.

An affirmative, "Definitely. Yes!" was the response from the facilitator of Institution 3. The facilitator qualified the response by adding, "Absolutely, they want to go back. They create interpersonal relationships." Students became aware of others who are from diverse and multicultural backgrounds, they started to develop a sense of belonging and of caring and wanting to contribute to society. Exposure to the external community promoted personal growth and the development of social responsiveness.

All five delegates at the ISETL conference indicated that the statement, service-learning cultivates social responsiveness in students and changes behaviour, is true. Service-learning goes beyond cultivating social responsiveness, and also develops a sense of solidarity in students. They become active contributors to citizenship through a reciprocal relationship.

An unexpected consequence of student preparation within the hidden community was that individual students were able to answer the question: How was I able to achieve the academic outcomes of the service-learning module? This question can be translated to other spheres of the academe where the answers thereto "You learned from them [fellow students] in simpler terms by listening to the way they understood it" (collaborative learning); "Additional info" (more resources); "Research" (self-discovery), can assist in achievement of outcomes.

When students were asked, What personal strengths of yours did the situation reveal? they were also asked to say, In what way did they affect the situation positively? The categorised answers mentioned by students were factors that enhanced the presentation itself, and factors 
that ensured good interaction with others. Confidence featured strongly, and most of the other feedback referred to the graduate attributes students need to display. In addition to "passion for teaching", and "presentation skills", a large number of categories can be associated with "management". These explanations can be the consequence of students' positive, can-do attitudes when they work with others; and of the students recognising that the group (hidden community) is a vehicle for their own advancement, and the well-being of the network of communities is the destination. Students' introspection and personal revelations with regard to this theme can be positive points of reference for handling similar situations in clinical and social arenas in the future.

Some of the subcategories clarify how the students' perceived strengths could also have unwanted results in different situations: "Good management skills" led to "Some did not like me much", and "Creativity" led to "Poor time management" and "Frustration". The information can also assist students to be more selective about their approaches to dealing with others in future endeavours. Students believed that their strengths could be improved if they were "Attentive to others", "learning from others" and "had more self-belief".

With reference to personal weaknesses, students' feedback showed that, through introspection, they identified and were able to interpret the positive influences of their perceived shortcomings on the success of the intervention. Weaknesses that were confessed can be associated with social cohesion and having high-quality interaction with the Grade12's. The group approach to service-learning demands that students compromise in some situations and take the lead in others whether in the hidden or the external community.

Table 1: Personal weaknesses and their positive effects

\begin{tabular}{|l|l|}
\hline Categories & In what way did the weakness affect the situation positively? \\
\hline Trust issues & Impatience motivated others \\
Cannot work under pressure & Did not influence the presentation as I was better prepared \\
Attentiveness & Improved listening \\
Perfectionist & Perfectionism motivated others \\
Lack of perseverance & Motivation from others \\
Selectivity of information & Detailed info presented \\
\hline
\end{tabular}

As displayed in Table 1, some students indicated that their perceived weaknesses, ironically, had a positive impact on the service-learning experiences, in that it lead to personal growth, social responsiveness and academic prowess. The category for which the rubrics provided the most feedback to overcome weaknesses was practise. In this instance, practise refers to a type of dress rehearsal, including more academic presentations, and the development of presentation skills and communication skills. Students were able to identify measures that would improve 
their perceived weaknesses, thereby confirming that personal growth had taken place.

The students reported that their personal values were reinforced through service-learning as a consequence of both personal and social affirmation. Personal affirmation involved improved confidence, improved self-belief and improved self-respect; whereas social affirmation was a result of being open to the different communities and doing something for the external community. These sources of enhancement of personal values can be seen as stimulating social responsiveness, which was also demanded by the societal value of respecting others and respecting others' opinions.

Students also reported that their personal beliefs were enhanced by personal and social affirmation. Personal affirmation comprised improved confidence, more patience and less selfdoubt. Personal beliefs were reinforced through interacting with other communities and treating people with respect, which was a consequence of social affirmation. For this theme, group work received mixed reviews; one student said that group work was "stupid", another said it was "good", one said that he/she does not need the group and two other students said that, "together we can do more".

The personal values that were perceived to have been challenged (as reported by students) were influenced by personal critique in a societal differentiation and demand paradigm. Personal critique was reported by students who mentioned confidence and self-belief; in the words of two students, "introspection improved". Societal differentiation of values occurred when students experienced leaving their comfort zones, and when students had to put the group first. Societal demands require that students show mutual respect, which represents the positive change in students' attitudes towards the community. Personal beliefs were challenged by personal critique elements, such as self-belief and trusting others. Societal differentiation that challenged students' beliefs related to students being exposed to cultures different from their own, that they are not familiar with in settings foreign to them. In reference to societal differentiation (as exemplified previously) within the hidden community students felt that some group members had "dodgy priorities". Challenges stemming from both personal critique and societal demands were addressed by students mentioning in both the reflections and reflection discussions the importance of delivering the message.

Grade 12 learners provided feedback on how to improve future interaction between students and themselves; one of the bigger categories was, More time should be spent in community, which is related to community responsiveness. The learners indicated that students needed to improve their "organisation". A large number of Grade 12 learners stated that students needed to improve their "confidence". The feedback helped students to identify areas that need attention, and facilitated self-awareness and personal growth (e.g. self-improvement 
and self-actualisation, self-confidence and self-esteem (Duckenfield and Swanson 1992, 5)). Grade 12 learners also indicated that "More interactive" sessions and "incorporating more games" would be of greater value.

Pedagogical regression through service-learning to advance the "pluroversity" approach, where extrinsic factors influence the policy of academic institutions and the way in which teaching, learning and assessment is done, also creates shared ownership of projects. The community's feedback on how to improve the interactions illustrate a move away from a paternalistic view of service-learning, from a traditional form of reciprocity, to the enriched form of reciprocity recommended by Enos and Morton $(2003,25)$. In the enriched form of reciprocity, the goal is collective, and not individual; power is shared, and it transcends selfinterest. This type of reciprocity enabled students to value the contribution of the Grade 12 learners to their (students') development.

\section{CONCLUSION, LIMITATIONS AND RECOMMENDATIONS FOR FUTURE RESEARCH}

Analysis of the definition of service-learning shows that the planning, rollout and interaction between radiography students and Grade 12 learners reflect all the elements mentioned in the definition. It can, therefore, be concluded that the interaction between the two groups described in this article can be described as being service-learning. However, during radiography servicelearning, Sigmon's statement that each participant would be both server and served, caregiver and recipient of care, contributor and contributed, did not realise to the extent expected.

Through service-learning interaction with the Grade 12 learners and the hidden community, students' academic knowledge and understanding improved, they experienced personal growth, and their social responsiveness increased. From students' reflective comments, such as "giving back to the community" and "helping others", it is clear that students' social responsiveness were enhanced due to them participating in service-learning. The same conclusion can be reached from the suggestions students made to "minimize such difficulties with the community". Students mentioned personal growth as a reason for their positive experiences.

Personal growth and increased social responsiveness also resulted from students being able to identify their own strengths and weaknesses when interacting with others. Strengths were factors that enhanced both the presentation itself and factors that promoted interaction with others. Students suggested how these strengths and weaknesses could be improved or overcome respectively. Students' responses to the final question of the reflection exercise illustrated social responsiveness, through their suggestions for improving the relationship 
between the university and the community through service-learning. Effective service-learning challenges preconceived ideas students may have about communities including the hidden community who have different cultural, socio-economic and literacy backgrounds. Pedagogical regression assisted students in identifying their own learning preferences and progressing back to a learner centred infantile self-discovery within a community of communities. Regressing teaching and learning in collaboration with such communities gave rise to social empathy, a rediscovery of the self, and lifelong engagement.

The service-learning interaction of the radiography students initially had a gemeinschaftlich profile; subsequent community exposure and feedback tilted the scales more towards gemeinschaftlich, as the values, beliefs, opinions, aspirations and social and academic needs of Grade 12 learners started to impact students. Students surrendered power by acknowledging to Grade 12 learners' Visit 2 feedback and adapting the third visit interaction to meet the learners' needs better, demonstrating enriched rather than traditional reciprocity.

Regarding academic reciprocity, students did not report learning academic work from the external community. Feedback from students confirms that the parties involved (radiography students and Grade 12 learners) did not function as both teachers and learners. Instead, academic reciprocity occurred between students within the hidden community (collaboration) and through self-discovery. This confirms the belief of Bringle and Hatcher $(2005,27)$, that there is not necessarily academic learning produced during service-learning. In this study it did, but in a different form. Within the hidden community and due to interactions with the external community, learning was made possible through research, by incorporating additional information sources, and by using a pragmatic and relevant approach to simplifying information.

Conclusions from the interviews with facilitators relate reciprocity to the development of soft skills and social responsiveness and, to a lesser degree, to the module outcomes. The facilitators did not link students' service experiences to exit-level outcomes and the specific outcomes indicated by Hurd (2006, Online). In this instance, revision, having to simplify information and having to respond to questions from the external community reinforced and enhanced students' knowledge. Further, the facilitators at Institution 2 created a link between reciprocity and critical thinking - students were learning while planning the intervention. The link mentioned by these facilitators can be attributed to the management module that students have to complete during their studies. This also means that, in order to address community needs, students had to reinvent the way in which they engaged with the learning material. Contrary to Hurd's explanation of reciprocity, the interaction between the students and the Grade 12 learners did not "increase and diversify the intellectual resources available to 
students", this was accomplished through the service-learning pedagogical process including interaction with the hidden community.

Students confirmed that academic reciprocity with the external community did not occur, though a different type of academic learning did take place. During this study, cognitive learning occurred though collaboration within the hidden community, research and simplification of information necessitated by pedagogical regression; psychomotor learning was facilitated through simulation and demonstration; and affective learning was the consequence of values, beliefs and convictions being reinforced and challenged throughout a network of communities within the service-learning partnership.

The results of data collected from a variety of participants, local and international, indicate that reciprocity during service-learning can be viewed as white light composed of different. Reciprocity needs to be redefined to multifacetly reflect holistic mutual development as a product of academically grounded praxis and immersion within a community of communities.

The number of local Radiography facilitators can be seen as a limitation since it was only 5. It should however be remembered that at the stage of data gathering not a lot of Radiography training departments in SA were engaged in service-learning. With the increased use of this teaching and learning approach this sample size can be increased. Using a focus group approach would have allowed for richer data gathering from the ISELT conference delegates.

\section{REFERENCES}

Bawa, A. 2003. Rethinking community-based learning in the context of globalisation. In Service in the $21^{\text {st }}$ century, ed. H. Perold, S. Stroud and M. Sherraden, 47-60. Johannesburg: Global Service Institute and Volunteer and Service Enquiry Southern Africa. https://www.ufs.ac.za/docs/ librariesprovider43/service-learning-documents/articles-documents/art_bawa-294-eng.pdf?sfvrsn $=$ af13f021_0

Bellner, M. and J. Pomery. (Ed.). 2005. Service-learning: Intercommunity and interdisciplinary explorations. Indianapolis: IUPUI Press.

Bringle, R. G. and J. A. Hatcher. 1995. A service-learning curriculum for faculty. Michigan Journal of Community Service-Learning 2(1): 112-122.

Bringle. R. G. and J. A. Hatcher. 2005. Service-learning as scholarship: Why theory-based research is critical to service-learning. Acta Academica Supplementum 3: 24-44.

Celio, I., J. Durlak and A. Dymnicki. 2011. A meta-analysis of the impact of service-learning on students. Journal of Experiential Education 34(2): 164-181.

Donahue, D. M., I. Bowyer and D. Rosenberg. 2003. Learning with and learning from: Reciprocity in service-learning in teacher education. Equity \& Excellence in Education 36(1): 15-27.

Duckenfield, M. and L. Swanson. 1992. Service-learning meeting the needs of youth at risk. National Dropout Prevention Center. Ref. No. 2103-22.

Enos, S. and K. Morton. 2003. Developing a theory and practice of campus-community partnerships. In Building service partnerships, ed. B. Jacoby, 20-41. Indianapolis, IN: Jossey-Bass.

Ertmer, P. A. and T. J. Newby. 2013. Behaviorism, cognitivism, constructivism: Comparing critical features from an instructional design perspective. Performance Improvement Quarterly 26(2): 43- 
71.

Furco, A. 1996. Service-learning: A balanced approach to experiential education. In Expanding boundaries: Serving and learning, ed. B. Taylor, 2-6. Columbia, MD: The Cooperative Education Association.

Garner, S. 2014. Photovoice as a teaching and learning strategy for undergraduate nursing students. Nurse Education Today 34: 1272-1274.

HEQC see Higher Education Quality Committee South Africa.

HEQC CHE see Higher Education Quality Committee South Africa. Council on Higher Education.

Higher Education Quality Committee South Africa. 2004. Criteria for institutional audits. Pretoria: Council on Higher Education.

Higher Education Quality Committee South Africa. Council on Higher Education. 2006. Servicelearning in the curriculum: A resource for higher education institutions. Pretoria: Council on Higher Education.

Hurd, C. A. 2006. Is service-learning effective? A look at current research. http://www.floridacompact.org/forums/viewtopic.php?t=1821\#p1829

Kolb, D. A. 1984. Experiential learning: Experience as the source of learning and development. New Jersey: Prentice-Hall.

Martinez-Mier, E. A., A. E. Soto-Rojas, S. M. Stelzner, D. E. Lorant, M. E. Riner and K. M. Yoder. 2011. An international, multidisciplinary, service-learning program: An option in the dental school curriculum. Education for Health, 11(online): 259. http://www.educationforhealth.net/ article. asp?issn $=1357-6283$; year $=2011$; volume $=24$;issue $=1$; spage $=259$; epage $=259$; aulast $=$ Martinez-Mier

Merz, C. and G. C. Furman. 1997. Community and schools: Promise and paradox. London: Teachers College Press.

Richardson, S. 2006. The power of service-learning. Techniques: Connecting Education \& Careers 81(1): 38-40.

Stanton, T. K. 1990. Service-learning: Groping toward a definition. In Combining service and learning: A resource book for community and public service, ed. J. C. Kendall, Vol. 1., 65-68. Raleigh, NC: National Society for Experiential Education.

Sigmon, R. L. 1996. Journey to service-learning. Experiences from independent liberal arts colleges and universities. Washington, DC: Council of Independent Colleges.

Vygotsky, L. S. 1978. Interaction between learning and development. From mind and society. Cambridge, MA: Harvard University Press. 